\title{
Los gobiernos progresistas de América Latina en el contexto internacional: una aproximación a sus límites'
}

\author{
Recibido: 19/02/2018 \\ Aprobado: 28/06/2018
}

\author{
OSCAR UGARTECHE \\ Universidad Nacional Autónoma de México \\ ougarteche@gmail.com
}

\begin{abstract}
RESUMEN
En el periodo del 2003 al 2017 fueron electos gobiernos progresistas con una agenda posneoliberal. Fatiga de reformas, exceso de ideología de mercado, poco respeto por las instituciones democráticas de parte de los gobiernos neoliberales, baja de los salarios, precarización laboral, incremento del empleo informal, desmantelamiento de los sindicatos y desenfado ideológico en los medios de comunicación oficiales saturaron a la ciudadanía. A mediados de la segunda década del siglo XXI, apenas una década después de haber llegado al Gobierno los partidos progresistas, estos comenzaron a perder la popularidad y las elecciones. Lo que se va a revisar en el presente texto es por qué ocurrió eso de manera casi simultánea, revisando variables económicas y políticas. En este texto haremos una revisión de algunas variables de los principales problemas económicos enfrentados, e igualmente se procederá a revisar los problemas políticos y sus variables para terminar con una conclusión sobre los problemas que plantean los gobiernos que intentaron aproximarse a políticas progresistas o al socialismo del siglo XXI.
\end{abstract}

Palabras clave: Gobiernos progresistas, economía, política.

\section{The progressive governments of Latin America in the international context: an approach to their limits}

\begin{abstract}
In the period from 2003 to 2017 progressive governments were elected with a post-neoliberal agenda. Fatigue of reforms, excess of market ideology, little respect for democratic institutions by neoliberal governments, low wages, job insecurity, increase of informal employment, dismantling of unions, and ideological self-assurance in the official media saturated the citizenship. In the middle of the second decade of the 21 st century, barely a decade after the progressive parties where elected to government, they began to lose popularity and elections. What is going to be reviewed in the present text is why this happened almost simultaneously, reviewing economic and political variables. In this text we will review some variables of the main economic problems faced and also proceed to review the political problems and their variables. The end is a conclusion about the problems posed by governments that tried to approach progressive policies or the socialism of the XXI century.
\end{abstract}

Keywords: Progressive governments, economícs, polítics.

1 Conferencia dada en la Universidad Nacional Mayor de San Marcos, como parte de un congreso sobre las economías de los países progresistas (Lima, 2017). 


\section{Los problemas económicos de los gobiernos progresistas}

\subsection{La lógica de crecimiento económico}

América Latina comenzó a crecer aceleradamente a inicios de la primera década del siglo empujada por los altos precios de las materias primas. Durante esa década, la correlación entre los crecimientos de los países del ASEAN+5 y América Latina y el Caribe era casi perfecta. Inclusive, cuando la crisis del 2008, ambas se cayeron de manera sincrónica como si fueron una sola economía. La recuperación se dio igualmente se manera sincrónica hasta que los precios de las materias primas comenzaron a descender. Ahora se sabe que los precios de las materias primas en particular y del oro en especial estuvieron relacionados con operaciones especulativas de la gran banca. El informe titulado Wall Street Bank Involvement with Physical Commodities, Majority And Minority Staff Report, Permanent Subcommittee on Investigations United States Senate, del 20 de noviembre del 2014, expuso la manipulación de precios de materias primas que había tenido lugar de parte de la gran banca. La otra cara de la medalla de esto fue el auge inusual de los precios de los mismos que los analistas del Banco Mundial y del Fondo Monetario Internacional (FMI), así como algunos latinoamericanos equivocadamente asignaron a la dinámica de China y al éxito de las reformas

\section{Gráfico 1}

LA DIVERGENCIA EN EL CRECIMIENTO DEL PIB

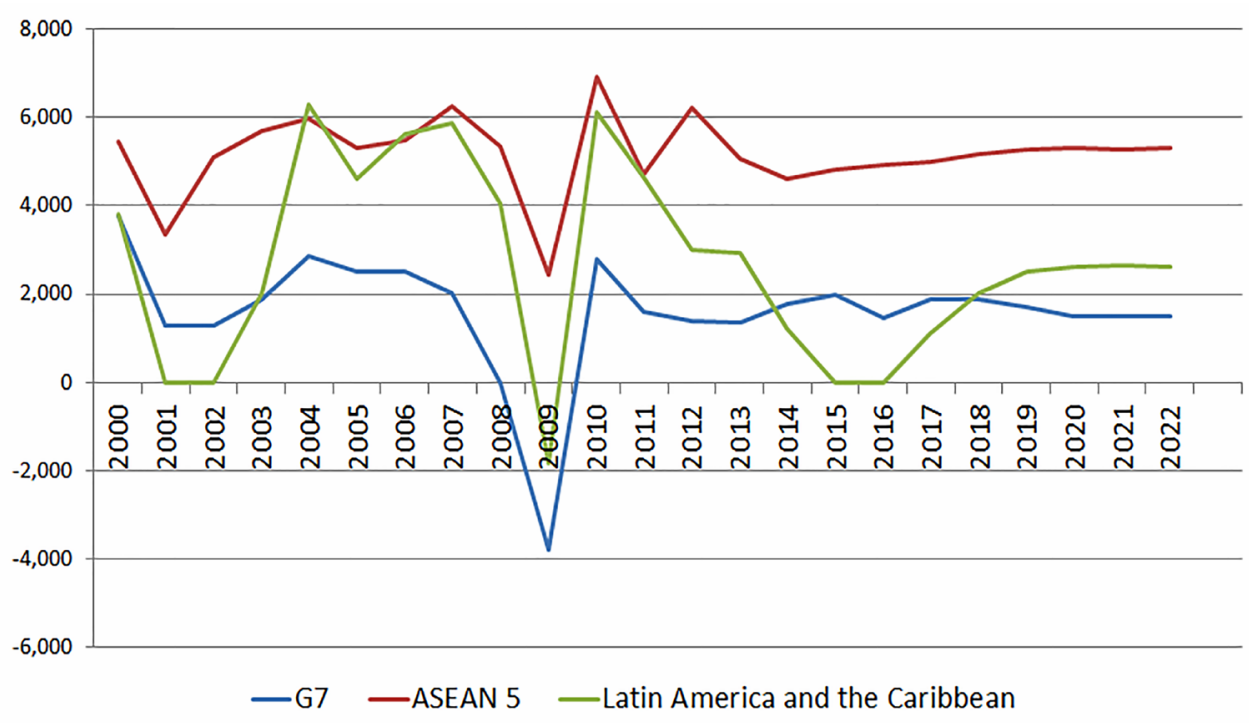


exportadoras. Hablaban del súper ciclo liderado por la demanda China cuando en realidad era un ciclo especulativo corto liderado por tres bancos.

El informe del Senado americano del 2014 sobre la conducta de la gran banca en el mercado de comoditas físicos después del 2008, año de la gran crisis, dice:

Hallazgos de hechos:

(1) Participar en actividades arriesgadas. Desde el 2008, Goldman Sachs, JPMorgan Chase y Morgan Stanley se han comprometido en muchos miles de millones de dólares de riesgos físicos, actividades de productos básicos, poseer o controlar, no solo vastos inventarios de productos básicos como petróleo crudo, combustible para aviones, combustible para calefacción, gas natural, cobre, aluminio y uranio, sino también negocios relacionados, incluidas las centrales eléctricas, minas de carbón, gas natural instalaciones y oleoductos y gasoductos.

(2) Mezcla de banca con comercio. Del 2008 al 2014, Goldman, JPMorgan y Morgan Stanley se involucraron en actividades físicas básicas que combinaban la banca con el comercio, beneficiándose de menores costos de endeudamiento y menor capital para la deuda ratios comparados con compañías no bancarias.

(3) Afectación de los precios. A veces, algunas de las compañías de holding financiero utilizan o se contempla el uso de actividades físicas de productos básicos, como la apuesta por la compra de electricidad en la bolsa, algunas operaciones giratorias, o un fondo propuesto negociado en bolsa respaldado por cobre físico, que tuvo el efecto potencial de manipular o influir en los precios de los productos básicos.

(4) Obtener ventajas comerciales. Ejercer el control sobre inmensas cantidades físicas de los productos básicos dieron acceso a Goldman, JPMorgan y Morgan Stanley a información de valor comercial no público que les podría haber proporcionado ventajas en sus actividades comerciales.

(5) Incurrir en nuevos riesgos bancarios. Debido a sus actividades físicas con productos básicos, Goldman, JPMorgan y Morgan Stanley incurrieron en riesgos múltiples normalmente ausentes de la banca, incluidos los riesgos de eventos operativos, ambientales y catastróficos, empeorados por la naturaleza transitoria de sus inversiones.

(6) Incurrir en nuevos riesgos sistémicos. Debido a sus actividades físicas con productos básicos, Goldman, JPMorgan y Morgan Stanley incurrieron en un aumento financiero, operativo, y en riesgos de eventos catastróficos, y enfrentaron acusaciones de ventajas comerciales injustas, conflictos de interés y manipulación del mercado, y problemas intensificados de ser demasiado grandes para administrar o regular, introduciendo nuevos riesgos sistémicos en el sistema financiero de los Estados Unidos.

(7) Usar límites de tamaño ineficaces. Protecciones prudenciales que limitan el tamaño de las actividades físicas de los productos básicos están plagadas de exclusiones y se aplican con falta de coordinación, incoherencia e ineficacia, lo que le permitió a JPMorgan, por ejemplo, mantener productos físicos con un valor de 
mercado de $\$ 17.4$ mil millones — casi el 12\% de su capital de nivel 1 -, mientras que, al mismo tiempo, calculaba el mercado el valor de sus tenencias físicas de productos básicos para cumplir con el límite de la Reserva Federal a solo \$ 6.6 mil millones.

(8) Falta información clave. Los reguladores federales y el público actualmente carecen de información clave sobre las actividades físicas de las empresas financieras como para formarse una idea precisa de la naturaleza y el alcance de esas actividades y proteger los mercados.

El resultado de estas actividades financieras extracurriculares de parte de la gran banca fue un auge brutal en los precios de las materias primas hasta que se iniciaron las investigaciones en el 2014, cuando se desplomaron.

Lo que se observó en las economías latinoamericanas fue un auge exportador sustantivo entre el 2009 y 2013, por esta razón, lo que aunado al anterior del 2003 al 2007, sumó una tasa de crecimiento del PIB exportador sustantiva. Así, todas las economías, progresistas y ortodoxas, siguieron el camino del crecimiento primario exportador con la volatilidad que esto conlleva, como señalara Prebisch en 1949. Los gobiernos progresistas no lograron cambiar el patrón de acumulación, permaneciendo sensibles a las variaciones en los precios de las materias primas.

\section{Gráfico 2}

PRECIO DE LAS PRINCIPALES MATERIAS PRIMAS

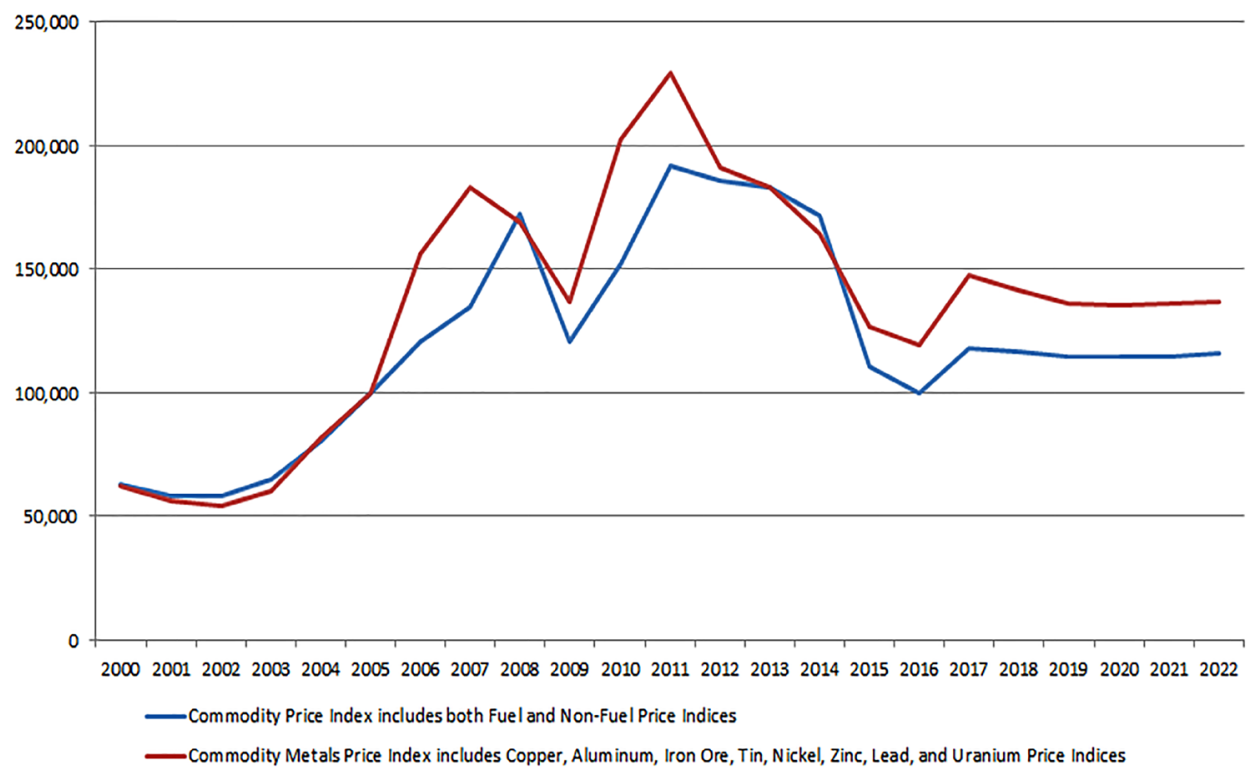


Al respecto, Rafael Correa dijo: "Básicamente estamos haciendo mejor las cosas con el mismo modelo de acumulación, antes que cambiarlo, porque no es nuestro deseo perjudicar a los ricos, pero sí es nuestra intención tener una sociedad más justa y equitativa". ${ }^{2}$ Al otro lado está la aseveración de Chávez: "Si nosotros no lográramos transformar estructuralmente el modelo rentístico capitalista que ha imperado en Venezuela desde siempre por un modelo productivo, diversificado, socialista, nunca estaríamos en condiciones de satisfacer las necesidades del pueblo". Es decir, estos dos líderes no tenían la misma visión sobre el patrón de acumulación que es la madre de los cambios políticos y sociales duraderos. El fracaso en lograrlo está en la base de sus límites políticos.

Harnecker (2011) se refiere a Chávez y dice: “La lección principal del proyecto chavista es la necesidad e importancia de combinar el socialismo con la democracia, no una democracia liberal, sino una democracia participativa y directa". En este campo, el tema no es el patrón de acumulación únicamente sino el tipo de democracia o ambas cosas.

Lula de Silva (2002) escribió sobre el patrón de acumulación en Brasil: "El sentimiento predominante en todas las clases y en todas las regiones es que el actual modelo se ha agotado. Por eso, el país no puede insistir en ese camino, bajo la pena de quedarse en un estancamiento crónico o incluso de sufrir, más temprano o más tarde, un colapso económico, social y moral". Lo que propone como alternativa allí es:

Se niega cualquier forma de continuismo, sea asumido o enmascarado. Quiere que el camino de la reducción de nuestra vulnerabilidad externa sea por el esfuerzo combinado de exportar más y de crear un amplio mercado interior de consumo de masas. Quiere abrir el camino de combinar el incremento de la actividad económica con políticas sociales consistentes y creativas. El camino de las reformas estructurales que de hecho democraticen y modernicen el país, haciéndolo más justo, eficiente y, al mismo tiempo, más competitivo en el mercado internacional. El camino de la reforma tributaria, que deshonra la producción. De la reforma agraria, que asegure la paz en el campo. La reducción de nuestras carencias energéticas y de nuestro déficit habitacional. La reforma de la jubilación, de la reforma laboral y de los programas prioritarios el hambre y la inseguridad pública.

La consecuencia de esto fue una ampliación del mercado interno, vía la mejora salarial, lo que eventualmente se enfrentó a la caída de los precios de las ma-

2 El Telégrafo, 15 de marzo del 2012. 
terias primas y el estrangulamiento de la balanza de pagos. La mejora interna pudo darse en Brasil mientras la restricción externa no existiera. La diferencia entre Brasil y los demás países progresistas es que tiene una bolsa de valores de tamaño mundial. La balanza de pagos brasileña se sostiene en parte por los flujos de capital de corto plazo que entran a la bolsa y por la inversión extranjera directa. Es decir que todo lo dicho en su Carta al pueblo está orientado a una modernización, pero no tomó en cuenta la variable financiera. El 2014 Brasil acumuló un déficit externo de 90900 millones de dólares, el peor resultado desde el 2001, antes que subiera el Partido de los Trabajadores (PT) al Gobierno. ${ }^{3}$ Esto derivó en los precios bajos de las materias primas. Además, se financió el déficit con un balance de la cuenta financiera que acumuló un saldo positivo de 99000 millones de dólares, con una inversión extranjera directa (IED) que alcanzó los 62500 millones de dólares. De este modo, el nivel de reservas internacionales permaneció estable y el tipo de cambio no se movió mucho. Las condiciones que hubo que darle al sector financiero para que esto fuera posible consistieron en nombrar a un banquero como ministro de Economía, quien buscó desde su nombramiento en el 2014 que la meta para los ingresos públicos superase los gastos en un valor equivalente como mínimo al 2\% del PIB para el 2016 y 2017. Esto se haría subiendo impuestos y reduciendo gastos públicos. Es decir, fue la misma política económica ortodoxa del resto del hemisferio aplicada en medio de una crisis de balanza de pagos generada por la caída de los precios de los commodities. Además, había un contexto de inflación creciente impactada por la devaluación del real derivada de la inseguridad política de las acusaciones de corrupción contra el Gobierno del PT. La inflación estaba comenzando a subir a sus niveles previos a la llegada del PT, por encima de 5\%, y se aplicó una fuerte política antiinflacionaria subiendo las tasas de interés y bajando el salario real en $10 \%$ entre el 2012 y 2014, y otra vez entre el 2014 y 2016. El salario mínimo interprofesional se redujo 20\% entre el 2012 y 2016.

Siendo una economía financiarizada, la tasa de interés es fundamental en la distribución del ingreso. Lo que logró el PT fue reducir la tasa de interés activa de $62.9 \%$ en nominal y $50.4 \%$ en reales (inflación de $12.53 \%$ ) en el 2002, y a $36.6 \%$ en nominal y $30.76 \%$ en reales (inflación de $5.84 \%$ ) en el 2012. Durante la administración de Dilma se redujo a $27.4 \%$ en nominal y $21.5 \%$ en reales (inflación de 5.91\%) en el 2013. Es decir, puesto desde el ángulo de la lucha de clases, el sector financiero perdió la mitad de sus ingresos entre el 2002 y 2013,

3 Véase: http://www.elmundo.es/internacional/2015/01/23/54c27163ca4741c1428b4579.html. 
mientras los salarios mínimos reales casi triplicaron habiendo subido de 95.1 euros en el 2002 a 257.5 euros en el 2012 y 250.8 euros en el 2013. Es decir, lo que logró el Gobierno del PT fue mejorar la distribución del ingreso quitándole al sector financiero una parte importante de sus ingresos. Tras la segunda elección de Dilma, a partir del 2014, la tasa de interés comenzó a subir aceleradamente y con el banquero Levy en el Ministerio de Economía en el 2016 había más que doblado en relación al 2013, con un 45.8\%. Es decir que los problemas de Brasil no fueron solo de precios externos, sino por la pugna entre el sector financiero y el sector real, entre el ingreso de los banqueros y el de la fuerza de trabajo. Las presiones de los banqueros sobre el PT se expresaron cuando Levy, doctorado en Economía de la Universidad de Chicago y banquero, fue nombrado ministro de Economía. Las medidas antipopulares que tomó precipitaron la caída del Gobierno en medio de un escándalo por corrupción que había afectado a la clase política brasileña en su conjunto.

\subsection{El crecimiento económico diferenciado}

El gráfico 2 muestra los dos auges de precios de materias primas y los dos desplomes. El segundo es el más importante porque regresaron los precios a su nuevo piso después de que el Senado americano obligara a los bancos a retirarse de los mercados físicos en el 2014. Encima de este fenómeno está el otro fenómeno especulativo que tiene que ver con la relación inversa entre la tasa de interés y el precio de las materias primas. Lo que se observa es un impacto de los anuncios del alza de la tasa de interés en los precios. En todo caso, las economías primarias son sensibles a las variaciones en los precios de los commodities. La interrogante es por qué los gobiernos progresistas no pudieron complejizar la lógica de crecimiento económico y producir con mayor valor agregado. Las dos excepciones son Brasil y Argentina. Este es un tema que recorre desde Venezuela, con amplios recursos para hacerlo, hasta Bolivia que no los tiene. Nadie logró complejizar el comercio ni modificar el patrón de acumulación, por lo que todos son sujetos a la enfermedad holandesa y sus consecuencias de tipos de cambio sobrevaluados. El caso brasileño es distinto por el papel inmenso que cumplen el sector financiero en esa economía

El crecimiento latinoamericano fue alto en el periodo 2003 a 2014 por las razones explicadas. Sin embargo, fue diferenciado. Mientras México, que no está en el cuadro, crecía alrededor de $2.1 \%$ al año de manera estable, el resto sufrió grandes variaciones. Lo que se aprecia en el cuadro son tres países pos- 
neoliberales con picos de crecimiento de casi 10\% como Argentina en el 2010 y Uruguay con crecimiento de 7\% casi estable entre el 2005 y 2011. No se ha incluido la data de Venezuela porque debido a la hiperinflación los datos están muy distorsionados en el último periodo. Bolivia tiene una tasa de crecimiento relativamente estable desde el 2006 hasta el 2017. Es la tasa de crecimiento más estable de la región con la tasa de crecimiento más alta. Inafectada por la crisis del 2008, no vio una caída de sus exportaciones dicho año ni vio una caída del PIB.

\section{Gráfico 3}

Crecimiento Del PIB Per CÁPITA

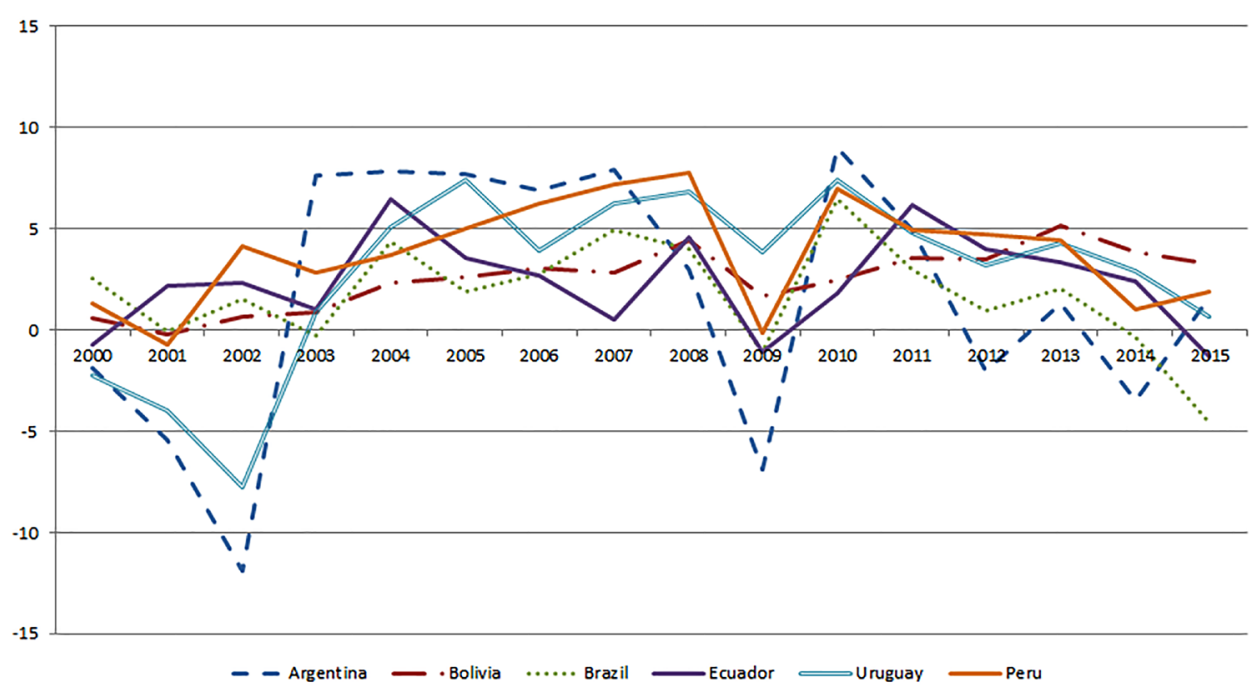

El modo como Bolivia crece en esta etapa tiene que ver con una redistribución del ingreso a partir de las regalías del gas, que fueron renacionalizadas en el 2006, y el contrato con Brasil de exportación de este combustible fue renegociado en mejores términos para ellos. Al darle a los campesinos más pobres una transferencia en efectivo, estos de inmediato consumen más en alimentos y eso echó a andar la producción agrícola de panllevar, lo que a su vez generó mercados nuevos y mayor riqueza en el campo. El resultado final fue una reducción de la pobreza muy sustantiva. El manejo del tipo de cambio, al revés de lo hecho en los demás países, se mantuvo estable, no permitiendo la apreciación del periodo 2005 al 2008 ni la depreciación del 2008 al 2017. Con un tipo de cambio relativamente estable, la inflación se mantuvo controlada y 
la redistribución hacia los sectores de menores ingresos sea vio consolidada. Esta ampliación de la producción de panllevar de parte de los sectores campesinos más pobres impactó positivamente también el mercado internacional, dada la población boliviana en Argentina. La exportación de alimentos creció hacia la Argentina a la par de la migración, con el beneficio que tiene eso sobre el ingreso de estos sectores.

La explicación para la estabilidad del crecimiento en el 2008 yace en que el grueso de los ingresos por exportaciones sale de dos contratos de venta de gas: uno con Argentina y otro con Brasil. Estos son contratos con precios fijos y con volúmenes predeterminados, de manera que no le hace los vaivenes del mercado internacional. Si se agrega que el tipo de cambio se mantuvo fijo, la dinámica de crecimiento macro se mantuvo estable y el PIB per cápita más que dobló en los años de Evo Morales y la pobreza extrema se redujo a un dígito y la total a alrededor de $20 \%$, menos de la mitad de lo que tenía antes del 2006. La depresión de precios del 2014 en adelante ha desacelerado levemente el crecimiento, pero continúa con la tasa más alta después de Panamá que tiene el crecimiento del PIB más rápido de América Latina.

A diferencia del Perú, que crece por inversiones mineras mayores, Bolivia parece tener sus inversiones mineras estables y su producción de gas estable, pero debe buscar nuevos yacimientos para mantener este crecimiento exportador a dichas tasas altas. Es el talón de Aquiles del régimen exitoso del Movimiento al Socialismo (MAS). Los nuevos yacimientos se encuentran en la selva amazónica y la población en dicha zona se opone a la explotación. De otro lado, los ecologistas han protestado por el intento de invasión a este territorio que está protegido como zona intangible. La reacción oficial es reprimir a los pobladores de la zona y a los ecologistas. La consecuencia es que al éxito de la política hay ahora un conflicto abierto sobre cómo continúa. La búsqueda de mercados ampliados dentro de América del Sur no le sirve a Bolivia en la medida en que su oferta productiva es muy limitada.

Los demás países observaron caídas del crecimiento del PIB per cápita, fundamentalmente como consecuencia de la caída de los precios de los commodities, cumpliéndose lo que dijo Prebisch sobre la vulnerabilidad del creciente primario exportador. Aún más, los términos de intercambio se han deteriorado en estos últimos años requiriendo por tanto mayores volúmenes de exportación a menor precio para mantener el mismo nivel de consumo. Esto es notable en Venezuela y en Ecuador, anclados en la exportación de petróleo al mercado internacional. 
Los países que aprovecharon el crecimiento de los precios internacionales fueron Brasil y Argentina, que lograron mejorar su aparato industrial interno y mejoraron drásticamente su nivel salarial aumentando el consumo interno de forma exponencial. Ese fue el motor estable del crecimiento mientras se incrementaban las exportaciones en volumen y precio. La restricción de la balanza de pagos no fue sentida sino cuando los créditos internacionales se cerraron tras la crisis del 2008 y el comercio exportador se desplomó. La recuperación se hizo ajustando el consumo y eso comenzó a ser un malestar en la ciudadanía. La baja del salario real a partir del 2010-2011 fue compensada con mayores créditos para consumo y para vivienda, pero la suma tuvo como resultado una mayor inflación en ambos países sin un levantamiento de la restricción externa. Encima se montó el retiro de capitales derivado de la crisis del 2008 en ambos países, lo que presionó sobre la balanza de pagos. Con más inflación y menos consumo, alguna parte de la ciudadanía de la clase media, otrora beneficiada, se vio perjudicada y se desafilió del apoyo al régimen, en cada caso, y eso explicaría la reversa inicial contra el partido de Gobierno. Luego, en ambos casos, se sumaron elementos de corrupción. Siendo el motor de UNASUR y de MERCOSUR, ambas iniciativas se vieron frenadas y con eso cualquier impulso de acción común frente a amenazas externas.

\subsection{La emigración}

La aparición de regímenes progresistas en América Latina tuvo un efecto inédito sobre la emigración que se observó entre las décadas de 1970, 1980 y 1990, por razones primero políticas y luego económicas. La década perdida expulsó profesionales desde América del Sur hacia el resto del mundo y fortaleció el mercado laboral regional con los beneficios que derivaron de las modificaciones de las leyes laborales y de la seguridad social para los países de la Comunidad Andina y del MERCOSUR. Esta transformación del mercado laboral ha permitido el movimiento poblacional dentro de Sudamérica sin perjuicio de los emigrantes, aunque con recelo de parte de la sociedad en el país receptor. Al igual que en Gran Bretaña con la llegada de los polacos que son iguales de color y hablan inglés perfectamente, pero trabajan más por menos salario, los migrantes peruanos y bolivianos a los países fronterizos generan recelo. Empero, con la llegada de los regímenes progresistas se redujeron los flujos migratorios. Donde no hay regímenes progresistas en Mesoamérica, los flujos estuvieron al alza hasta el 2015, cuando comenzaron a estabilizarse por efecto de las políticas antimigratorias es- 


\section{Gráfico 4}

\section{FLUJOS MIGRATORIOS}

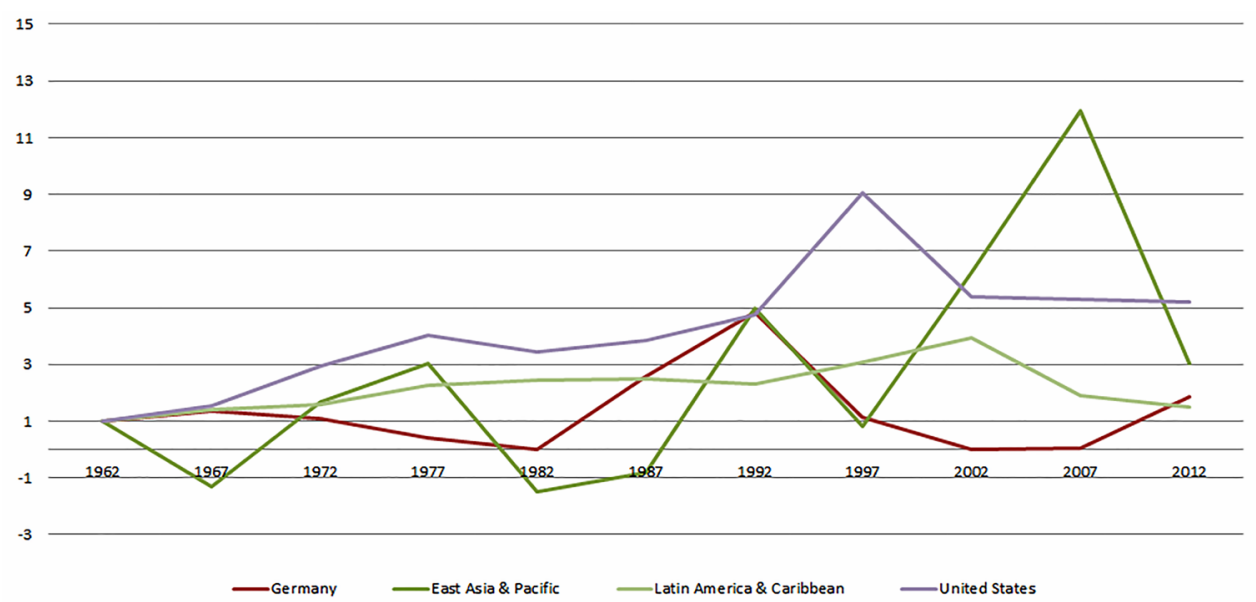

* Total of migrants during the period, that is, the total number of immigrants less the annual number of emigrants. Source: United Nations Population Division, World Population Prospects / WDI.

tadounidenses. Los mesoamericanos migran al norte, los sudamericanos migran dentro de Sudamérica y al resto del mundo, incluyendo el norte.

La reducción de la migración es un aporte fundamental tras dos décadas de fugas de cerebros, dado que el grueso de la emigración sudamericana es profesional, aunque vaya a Europa a hacer trabajos sencillos. En las universidades hay dos generaciones vacías entre los viejos maestros y los jóvenes que optaron por quedarse porque sus universidades tenían condiciones. Este cambio fue muy importante porque le ganó el apoyo de nuevas masas ciudadanas a los gobiernos de parte de los jóvenes profesionales que no emigraron y renovó la generación que apoyaba a los regímenes progresistas. En muchos casos, como Uruguay, por ejemplo, la masa que apoya al Frente Amplio es una masa muy mayor en un país que tiene una población joven reducida como efecto de las emigraciones.

La presencia importante de gente joven en los países donde hubo regímenes progresistas renovó la agenda progresista e introdujo, por ejemplo, los temas de los derechos sexuales y reproductivos como son el aborto y los derechos LGTBI. Ante las novedades en la agenda política juvenil, algunos gobiernos dieron su apoyo y modificaron las leyes correspondientes de aborto y de matrimonio igualitario (Argentina y Uruguay), mientras Bolivia y Ecuador se trancaron en contra. En Venezuela no es tema de debate político abierto y en Nicaragua comenzó el FSLN con una política antiderechos sexuales y reproductivos, pero debió recular ante el peso de sus jóvenes. 


\subsection{El medio ambiente y el extractivismo}

Los temas ambientales han ganado peso en las agendas progresistas. Los ecologistas han buscado soluciones más radicales que los ambientalistas, en un contexto donde los gobiernos se encuentran con el tema ambiental en la punta del discurso. Así, el Gobierno ecuatoriano se eligió con un discurso ecologista y se transformó lentamente en uno ambientalista, difiriendo el tema de las reservas naturales y de la contaminación derivada de la producción extractiva, minera y petrolera en particular.

El calentamiento climático ha traído consigo desastres naturales de mayor envergadura con niveles de destrucción de infraestructura que cuestan al fisco mucho reponer. De otro lado, la ciudadanía que vive en los centros a minutos o alrededores observa cómo se extraen las riquezas naturales, pero constatan que siguen siendo igual de pobres y encima están más contaminados. Esto ha radicalizado la agenda progresista que en algunos casos es resistida con militancia, como en Bolivia, donde el Gobierno se enfrenta a la población sobre esta materia, pero no resuelve su postura frente a los temas ambientales. El modelo de crecimiento sigue siendo extractivo y primario exportador. En el mismo sentido, el Gobierno argentino permitió la apertura de una mina en los glaciares de los Andes con la destrucción ambiental que eso implica. En Brasil, el Gobierno del PT estuvo del lado de la deforestación de la Amazonía en el nombre del progreso y de ganar terreno de cultivo para la soya. El Gobierno nicaragüense aprobó la construcción de un canal interoceánico que en primera instancia ha conllevado protestas por la destrucción ambiental que va a implicar. Esta resiliencia de los gobiernos progresistas a los temas ambientales les ha restado apoyo juvenil en las zonas afectadas $\mathrm{y}$, sobre todo, les ha restado presencia internacional en un sistema global donde la agenda ambiental está por encima de todo. Finalmente, los gobiernos progresistas siguieron con el mismo patrón de acumulación que los demás.

\subsection{La integración regional}

En la primera década del siglo XXI, hubo un auge integracionista en busca de una mayor autonomía frente al imperialismo norteamericano. Los Estados Unidos revivieron el plan del secretario de Estado Blaine de 1889, en la primera conferencia interamericana, de hacer un tratado continental de libre comercio, con una moneda única (la suya), envalentonado por el éxito del Tratado de Libre Comercio de América del Norte (1994). George Bush padre y Bill 
Clinton promocionaron el ALCA que los países progresistas unidos derrotaron en el 2005, con el apoyo de Brasil.

Esto abrió nuevamente una brecha entre los aires que miran al Atlántico y los que miran al Pacífico. Los primeros ya estaban reunidos en torno al MERCOSUR desde 1991 y acentuaron el ritmo de su integración llegando en el 2008 a operar con sus propias monedas, sin pasar por el dólar americano. Al otro lado Perú, Chile y Colombia, en el 2006, se reunieron para lanzar la Alianza del Pacífico con México. La condición de estos países que miran al Pacífico es que tuvieran un tratado de libre comercio con los Estados Unidos. Así, lentamente, los países que miran al Pacífico firmaron tratados de libre comercio entre sí y tratados de movimientos de carga y de personas, eliminando las exigencias de visas. Con Sudamérica partida en dos, entre Mercosur y la Alianza del Pacífico, el Gobierno argentino se aventuró a lanzar la idea de UNASUR. Esta tuvo el respaldo pleno de Hugo Chávez y de Néstor Kirchner, así como de Lula da Silva en Brasil y de Rafael Correa en Ecuador con la presencia tímida de Bolivia. Simbólicamente se establecieron las oficinas de UNASUR en Ecuador, en una ciudad llamada La Mitad de Mundo. El objetivo de UNASUR era sacar a estos gobiernos de la férula de los Estados Unidos y utilizar el espacio para un arbitraje político regional. Entre lo primero que logró fue la salida del Gobierno americano de Bolivia, después de varios intentos de derrocar al Gobierno de Morales, al identificar quiénes estaban detrás de los intentos de golpe.

Producto de este mismo estado de ánimo, se promovió la arquitectura financiera del sur, que tenía como objeto crear un banco de desarrollo autónomo de Washington —el Banco del Sur-, un fondo de estabilización cambiario y una unidad de cuentas (peso sudamericano) para el comercio intrarregional identificado en ese momento como en auge. Las resistencias del Gobierno brasileño fueron el freno a esta iniciativa apoyada por siete países sudamericanos, menos Perú, Colombia y Chile. Sin duda, la iniciativa reconocía las diferencias entre Mesoamérica y Sudamérica, y ponía la frontera política en Panamá.

Este esfuerzo de integración fue percibido por los países del Pacífico primario exportadores como una amenaza al status quo y un factor de desestabilización en las relaciones con los Estados Unidos. Puesto en estos términos, había los países alineados con los Estados Unidos y sus tratados de libre comercio y los demás. Este fue un tema que dividió a Sudamérica y que finalmente terminó cuando los regímenes que lo impulsaban desaparecieron y los Estados Unidos reforzaron el control territorial sobre el área, esta vez con bases militares en casi todos los países. 


\subsection{La deuda pública externa}

Un tema delicado después de la crisis de la década de 1980 ha sido el nivel de endeudamiento y la interrogante de si la deuda ayuda o frena al desarro1lo. Sin duda, el crédito para la construcción de infraestructura necesaria es vital, en cantidades mesuradas en relación con las exportaciones. El problema detectado en la década de 1990 fue que no se sabía el uso de los créditos ni se conocía cómo se habían llevado a cabo las negociaciones. Esto llevó al Gobierno argentino de Néstor Kirchner, por ejemplo, a enfrentar los impagos dejados por los gobiernos peronistas salientes que gobernaron durante diez años con tipo de cambio fijo. Dicho Gobierno recompró sus bonos de deuda externa al $45 \%$ de su valor y la economía argentina pudo relanzarse. El incremento de la deuda argentina entre 1999 y 2001 había sido causada por la necesidad de mantener el tipo de cambio fijo, según lo pactado con el FMI. Eso era un contrasentido como fue que el FMI acompañara y propiciara que el país se endeudara masivamente para mantenerlo estable cuando el principal socio comercial, Brasil, se había devaluado de uno a tres reales por dólar. La consecuencia fue que los dólares que ingresaban por estos créditos oficiales iban a parar a los bancos comerciales que a su vez los retiraban físicamente del país a través del puente de Colonia y los depositaban en Uruguay, enton-

\section{Gráfico 5}

DeUda EXTERNA PIB DE ECONOMÍAS EMERGENTES

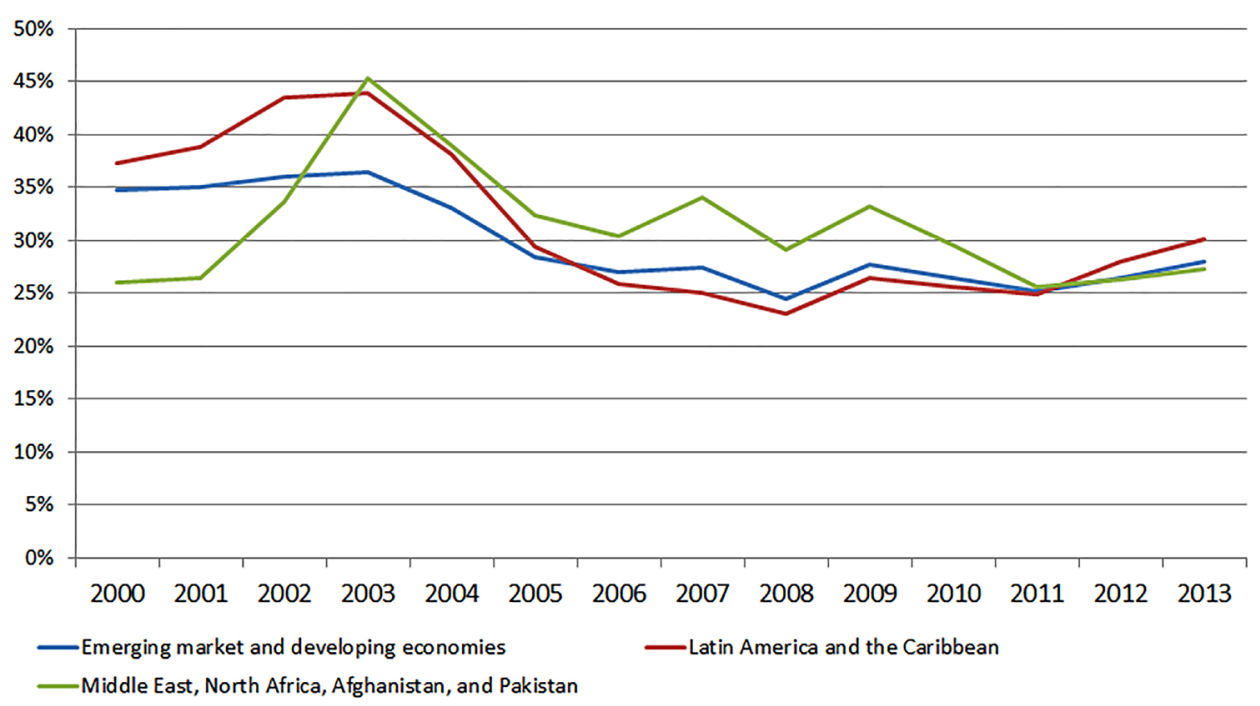


ces un paraíso fiscal. Por esta razón se encontró que recomprar esos bonos a esa tasa era una buena política.

Esta idea fue seguida por el Gobierno de la Revolución Ciudadana en Ecuador, que pidió una auditoría de la deuda para ver si existían o no deudas ilegitimas. Desafortunadamente para la iniciativa de auditar la deuda, el Gobierno ecuatoriano aprovechó para declarar que toda la deuda era ilegitima (lo cual hizo la auditoría inútil) y pasó a recomprar toda su deuda al 25\% de su valor nominal. Con eso encontró espacio de políticas fiscales para crecer. La primera consecuencia fue que esta idea quedó deslegitimada. La segunda fue que cuando Ecuador necesitó créditos, su riesgo país era muy alto y la tasa de interés altísima. El regreso de Ecuador al mercado financiero fue utilizando el oro como garantía y la supervisión estricta del FMI.

De todos modos, tanto los países progresistas como los neoliberales han utilizado poca deuda externa en las dos primeras décadas del siglo XXI y mantienen altos niveles de reservas internacionales, garantizando estabilidad cambiaria hasta donde esto es posible con un mercado cambiario y una balanza de pagos abierta. Argentina puso control de cambios por la velocidad con la que se fugaban los capitales, lo que lo convirtió en una excepción. La fuga de capitales argentina fue evaluada por el Gobierno de Macri en 400000 millones de dólares.

\subsection{La distribución del ingreso}

La evidencia muestra que entre el 2003 y 2014 hay una mejora sustantiva de la distribución del ingreso. Esto quiere decir que hubo un mejor reparto de los ingresos y que los salarios reales mejoraron sustantivamente. También quiere decir que los programas de transferencia directas a las familias en pobreza extrema funcionaron bastante bien complementando la mejora del salario real. En muchos casos, esto se hizo frenando las tasas de interés bancarias a niveles más parecidos a los internacionales. La reducción de la tasa de interés en Brasil y Argentina fue masiva, habiendo bajado de niveles cercanos al 50\% reales hasta un piso cercano al $10 \%$ reales entre el 2002 y 2014 . Brasil muestra la peor distribución del ingreso del subconjunto de países, pero con una mejora del Gini de 0.6 a 0.5 . Tras el derrocamiento del Gobierno del PT, una de las primeras leyes aprobadas fue congelar los gastos sociales los próximos treinta años, lo que asegura un retorno a un Gini de 0.6 o más.

Argentina, que en el 2002 tenía un Gini análogo al del Perú de 0.54, tuvo una mejora hasta 0.42 , mientras que el Perú, con políticas neoliberales, mejoró 
Gráfico 6

LOS PROGRES MEJORAN EL GINI

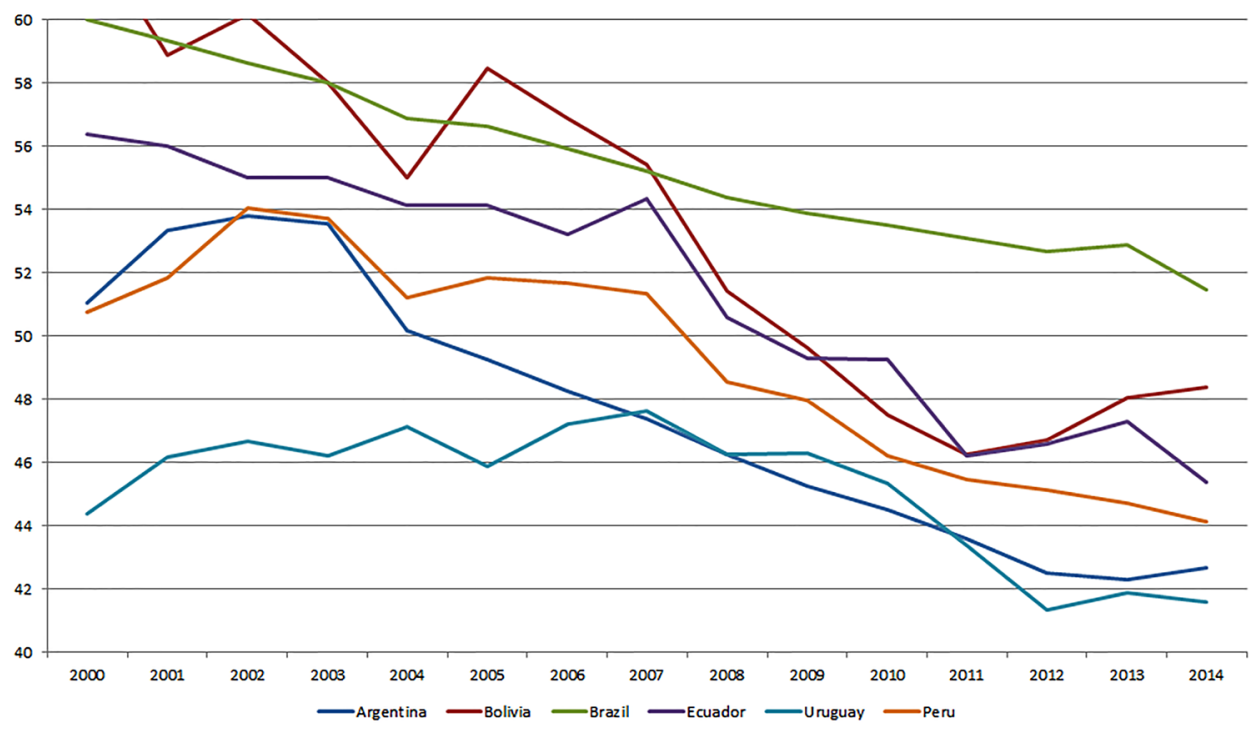

a 0.44 entre el 2002 y 2014. Esto abre la interrogante sobre si la mejora de los Gini fue fruto solo de las políticas sociales y salariales o si la mejora del ingreso nacional con mejoras salariales fue la clave. Los programas de transferencias directas parecen haber sido aplicadas por ambos si bien en unos países esas transferencias se convierten en aumento de la producción y demanda interna y en otros en importaciones. En el caso ecuatoriano, el Gini mejora desde el año 2007 no dejando la menor duda de que está relacionado con el Gobierno de la Revolución Ciudadana. Uruguay es el país con la mejor distribución de ingreso de la muestra con 0.44 y mejoró a 0.41 en ese periodo. No hay duda de que los gobiernos progresistas mejoraron la distribución del ingreso y en algunos casos lo hicieron a costa del sector financiero. Lo que es menos evidente es si los países que siguieron las políticas neoliberales no mejoraron también su distribución por otras vías o si todos siguieron las mismas vías al mejorar salarios reales y hacer transferencias, lo que les quitaría el monopolio, como el ejemplo contrafactual peruano muestra.

Esto lleva a la interrogante sobre el cambio entre los modelos de crecimiento primario exportadores y sus efectos. En la medida en que los precios de los commodities no son afectados por los salarios, bajar estos últimos no mejora la competitividad nacional. En las economías más industrializadas del 


\section{Gráfico 7}

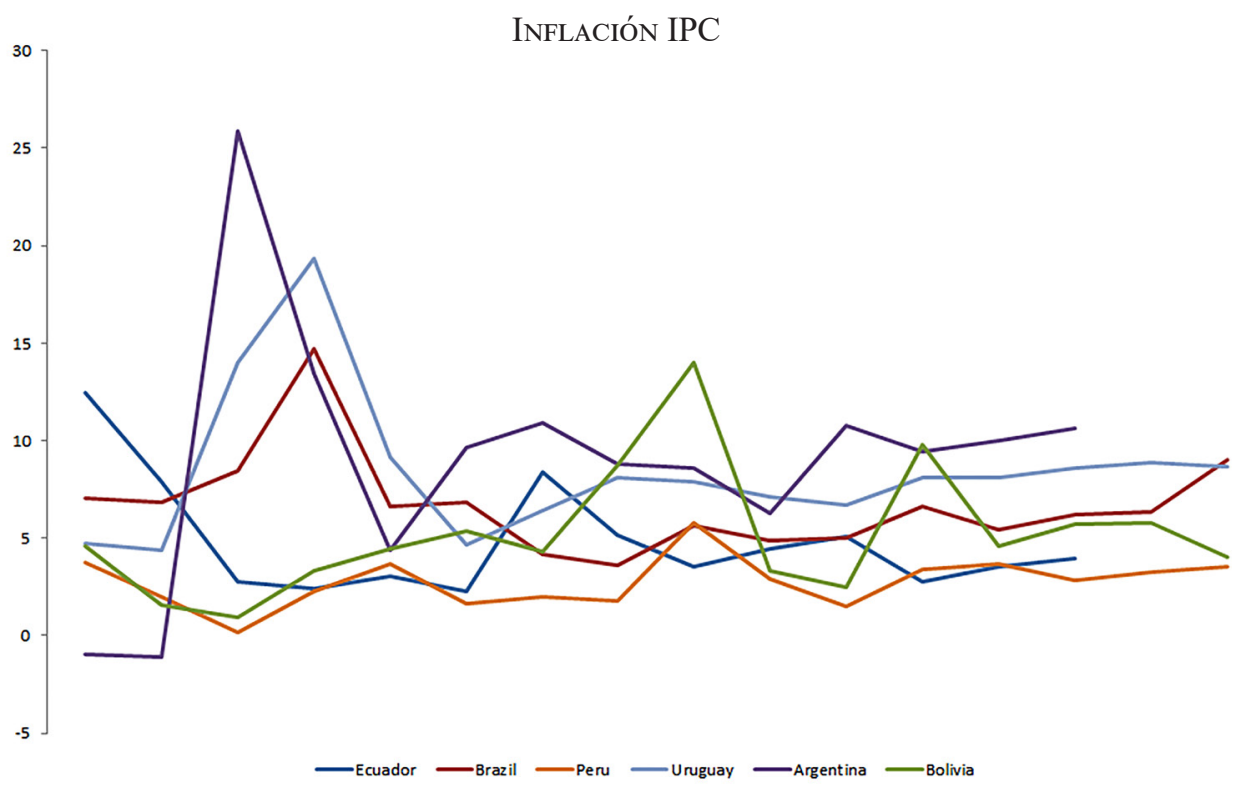

Atlántico el tema salarial es diferente. Lo que se observa en las economías primarias de la costa del Pacífico es que la masa salarial bajó en el PIB mientras que en los países progresistas subió, es decir, no solo hubo una mejora del salario real sino hubo más fuerza de trabajo contratada formalmente, con sus derechos laborales respetados, lo que no ocurrió en el caso de los países de la Alianza del Pacífico.

La gran diferencia por lo tanto tiene que ver con la calidad de empleo ofrecida en los países progresistas versus la ofrecida con los de la Alianza del Pacífico. Esta diferencia le hace a la naturaleza política del régimen, pero no a la del patrón de acumulación que como se ha visto continúa siendo primario exportador, altamente contaminante y basado en el despojo.

\subsection{La economía pública}

La muestra de países progresistas señala que en general tienen una tasa de inflación por encima de las tasas consideradas referenciales de entre $2 \%$ y $3 \%$. Estas tasas más altas tienen que ver con políticas monetarias más laxas y con políticas crediticias expansivas dirigidas hacia los sectores de menores ingresos, así como hacia el sector público. Esto quiere decir que las mejoras en la 
distribución del ingreso van acompañadas con más inflación y que la inflación no resta las mejoras en las condiciones de vida de la población.

Lo que detona la pérdida de afiliación al Gobierno está en las políticas de ajuste, cuando intentan bajar la tasa de inflación, como se vio en Brasil después del 2014. La población puede vivir con inflación mientras sus niveles de vida no se vean afectados. Cuando lo están, sea porque la inflación se desboca (caso observado de Venezuela) o porque se frena o reduce el salario real por el ajuste económico, entonces se produce la desafiliación. Es decir que no es la inflación misma sino sus consecuencias en términos de ajustes. La interrogante es sobre los tipos de ajuste implementados: si son sobre el consumo, son adversas a la población; si son sobre la recaudación fiscal, presionan a los sectores más ricos cuando se trata de ajustar impuestos directos; si son sobre impuestos indirectos, igualmente recaen sobre la población y tienen el mismo efecto adverso sobre la desafiliación al régimen.

Debe resaltarse el caso de Ecuador que renunció a tener una política monetaria en el 2000 y se dolarizó, igual que Panamá y El Salvador. El objeto de la dolarización era hacer converger la inflación con la de los Estados Unidos. Esto sin embargo no ocurrió y tiene una inflación baja, pero mayor a la de la moneda circulante en su país. El haber perdido el manejo de la política monetaria ha hecho que cuando los países vecinos con los que comercia tienen variaciones cambiarias, ellos deben poner restricciones arancelarias temporales para compensar las diferencias de costos. Esto impacta adversamente sobre los esquemas de comercio regionales y finalmente frena su tasa de crecimiento. La dolarización ha dejado a la economía ecuatoriana colocada con un solo instrumento de manejo: el fiscal, que tiene como restricción el acceso al crédito internacional y su costo.

Lo que se observó en Ecuador es que todos los proyectos de desdolarización traían el peligro de una corrida de los depósitos en dólares que dejaría la posición de caja del Banco Central vacía, lo que generaría una masiva devaluación luego de la resucretización. Este es un freno real a la economía de dicho país para recuperar una política monetaria propia y tener políticas crediticias expansivas como efectuaron el resto de los países.

\section{Los problemas políticos de los países progresistas}

Los gobiernos progresistas fueron electos en América Latina en los primeros años del siglo XXI tras un cansancio de las reformas estructurales del Banco 
Mundial. La privatización y desregulación a ultranza fabricó nuevos pobres y generó desesperanza y aumento de la migración. Conflictos sociales como el Caracazo entre el 27 de febrero y el 6 de marzo de 1989 o la Guerra del Agua en Cochabamba el 2000 dieron fruto en movimientos políticos de respuesta a la privatización de los bienes públicos. Las agendas de estos movimientos fueron por lo tanto de protección de los bienes públicos y de reconceptualización de la función del Estado en medio del proceso privatizador y del sentido común hayekiano sobre la construcción de la democracia a partir de la privatización del Estado.

Comenzó con la llegada al Gobierno de Hugo Chávez en Venezuela en 1999 y fue seguido por la elección de Lula da Silva en Brasil en el 2002; luego le siguieron Néstor Kirchner en Argentina en el 2003, Tabaré Vásquez en Uruguay en el 2005, Evo Morales en Bolivia en el 2006, y Rafael Correa en Ecuador en el 2007. Fernando Lugo de Paraguay fue el último electo en el 2008, pero el de más corta duración, siendo destituido en el 2012 a través de un golpe de Estado parlamentario, análogo al que derrocó a Dilma Rousseff de Brasil en el 2016.

En la presente sección revisaremos los siguientes aspectos políticos de los gobiernos progresistas del siglo XXI.

1. Las alianzas electorales

2. El caudillismo

3. La reelección permanente

4. La falta de renovación generacional

5. La corrupción

6. El socialismo del siglo XX

\subsection{Las alianzas electorales y los gobiernos progresistas}

Un problema que aparece con frecuencia en los análisis sobre los gobiernos progresistas y en sus críticas es que son muy moderados. La fantasía es que ganar las elecciones representa tomar el poder. Sin embargo, el grueso de los gobiernos progresistas fueron electos por una base pluriclasista y con alianzas políticas multipartidarias (ver tabla 1).

La lista de países reseñados es la siguiente:

- Uruguay: Frente Amplio (2005-2020) de Tabaré Vásquez, Pepe Mujica y Tabaré Vásquez. Renovado cada cinco años.

- Bolivia: Movimiento al Socialismo de Evo Morales (2006-). Reelecto. 
- Ecuador: Revolución Ciudadana de Rafael Correa (2007-2017) y Lenin Moreno (2017-2022). Renovado.

- Brasil: Partido de los Trabajadores de Lula da Silva (2002-2014) y Dilma Rouseff (2014-2016). Renovado.

- Venezuela: Hugo Chávez (1999-2013) con las Fuerzas Armadas y Nicolás Maduro con el PSUV (2013-). Maduro reelecto indefinidamente y reemplazando a Chávez por defunción.

- Argentina: Frente por la Victoria de Néstor Kirchner (2003-2007) y Cristina Fernández (2008-2016) con el peronismo de izquierda. Renovados.

- Nicaragua: Frente Sandinista de Daniel Ortega (2006-). Reelecto indefinidamente.

La mayor parte de los partidos de Gobierno en los países progresistas están aliados con otros partidos políticos que pueden o no ser progresistas. Esto trae como cola que algunos nombramientos a ministerios o bancos centrales vienen de canteras teóricas políticas distintas y en muchos casos en contraposición a la del presidente. Esto generó en el caso de Brasil un equipo liberal liderado por Santiago Levy en el Ministerio de Economía en el periodo que antecedió al derrocamiento a Dilma.

Hay gobiernos menos mezclados como el ecuatoriano y el venezolano que parecen tener más coherencia política ideológica dentro del aparato de Gobierno. El boliviano tiene una mezcla extraña de dos partidos de poca tolerancia a la diferencia: el falangista, que proviene de la década de 1930, y Túpac Katari, que viene de la guerrilla. Sin embargo, parecen haber construido una idea política común y actúan en conjunto. Argentina contenía una amalgama de partidos progresistas y tenía a su izquierda una oposición radical antiperonista. Esta última se juntó en varias ocasiones con la oposición antiperonista de derecha para bloquear las medidas del Gobierno de FPV, como las retenciones a la exportación de soja. Fue el vicepresidente de Cristina Fernández quien lideró en el Congreso la lucha contra las retenciones a las exportaciones de soja y el girasol: "La Resolución 125, como se le conoce, provocó la salida del entonces ministro de Economía, y el alejamiento definitivo del Poder Ejecutivo del entonces vicepresidente de la nación, Julio Cleto Cobos, con su recordado voto ‘no positivo' en el Senado. La decisión del extitular de la Cámara Alta marcó para la década kirchnerista una de las pocas batallas donde debió aceptar la derrota". ${ }^{4}$

4 Véase: https://www.eltribuno.com/salta/nota/2013-5-24-21-54-0-el-conflicto-con-el-campo-una-delas-pocas-batallas-perdidas-del-kirchnerismo. 


\section{Tabla 1}

LOS GOBIERNOS PROGRESISTAS EN EL PODER

\begin{tabular}{|c|c|c|}
\hline País & $\begin{array}{l}\text { Periodo de } \\
\text { Gobierno }\end{array}$ & Organización política \\
\hline Argentina & $\begin{array}{l}2003-2007 \\
2007-2011 \\
2011-2015\end{array}$ & $\begin{array}{l}\text { Frente para la Victoria, contiene al Partido Justicialista (peronista), } \\
\text { el Partido Intransigente, el Frente Grande y el Partido Comunista, } \\
\text { el radicalismo y vertientes socialistas. }\end{array}$ \\
\hline Bolivia & $\begin{array}{l}2005-2009 \\
2009-2014 \\
2014-\end{array}$ & $\begin{array}{l}\text { MAS, deviene de Falange Socialista Boliviana y Movimiento Indí- } \\
\text { gena Túpac Katari. }\end{array}$ \\
\hline Brasil & $\begin{array}{l}2002-2006 \\
2006-2010 \\
2010-2014 \\
2014-2016\end{array}$ & $\begin{array}{l}\text { Partido del Trabajo, es un partido sindicalista que gobernó con el } \\
\text { Partido Liberal, Partido Comunista del Brasil, Partido de la Mo- } \\
\text { vilización Nacional, Partido Comunista Brasileño, Partido Verde. } \\
\text { En la elección del } 2014 \text { la alianza varió: Partido del Movimiento } \\
\text { Democrático Brasileño, Partido Democrático, Partido Progresis- } \\
\text { ta, Partido de la Republica, Partido Democrático de los Trabajado- } \\
\text { res, Partido Republicano Brasileño, Partido Republicano de Orden } \\
\text { Social y Partido Comunista del Brasil. }\end{array}$ \\
\hline Ecuador & $\begin{array}{l}2007-2009 \\
2009-2013 \\
2013-2017 \\
2018-\end{array}$ & $\begin{array}{l}\text { La Revolución Ciudadana no tiene partidos políticos como ante- } \\
\text { cedentes. }\end{array}$ \\
\hline Nicaragua & $\begin{array}{l}2007-2012 \\
2012-2017 \\
2017-2021\end{array}$ & $\begin{array}{l}\text { Frente Sandinista para la Liberación Nacional. Se fundó en } 1961 \text { y } \\
\text { se transformó en un partido de masas en } 1990 .\end{array}$ \\
\hline Uruguay & $\begin{array}{l}2005-2010 \\
2010-2015 \\
2015-\end{array}$ & $\begin{array}{l}\text { Frente Amplio, que contiene al Partido Socialista, Partido Comu- } \\
\text { nista, Democracia Cristiana, Movimiento Popular Frente Analista } \\
\text { (disidente Blanco) y el Movimiento Pregón (disidente Colorado). }\end{array}$ \\
\hline Venezuela & $\begin{array}{l}1999-2007 \\
2007-2012 \\
2011-\end{array}$ & $\begin{array}{l}\text { Movimiento Quinta República, sin pasado político visible. Se fu- } \\
\text { sionó con el Partido Socialista Unificado de Venezuela que reúne } \\
\text { al Movimiento Electoral del Pueblo, Movimiento Independiente } \\
\text { Ganamos Todos, Unidad Popular Venezolana, Independientes por } \\
\text { la Comunidad Nacional y la Liga Socialista. Después se inscribie- } \\
\text { ron Patria Para Todos, Por la Democracia Social, el Movimiento } \\
\text { Tupamaro y el Partido Comunista de Venezuela. }\end{array}$ \\
\hline
\end{tabular}

Fuente: Elaboración propia.

Estos conflictos intragobierno, por razón de las alianzas electorales que los llevaron al triunfo, al final han terminado debilitándolos. Son alianzas no necesariamente entre afines políticos, como en el caso del PT con el Partido Liberal, sino por conveniencia. Cuando estas se rompen, destrozan la línea de Gobierno. 
Pero también tienen un rol dentro del Gobierno de entorpecer aquello con lo que están en desacuerdo y ayudan a desdibujar el proyecto político progresista.

\subsection{Caudillismo}

Una debilidad de los gobiernos progresistas en la región es que están liderados por caudillos que en el mejor espíritu del siglo XIX controlan el partido y el poder. Al respecto, Castro (2007, p. 9) dice:

El origen de la palabra caudillo viene del diminutivo latino caput, que significa "cabeza", "cabecilla", y aunque no existe una definición actual única e incontrovertible, tanto en términos académicos como populares el término evoca al hombre fuerte de la política, el más eminente de todos, situado por encima de las instituciones de la democracia formal cuando ellas son apenas embrionarias, raquíticas o en plena decadencia. Caudillismo e institución democrática son elementos situados en los extremos de una línea ascendente de la evolución política en donde el primero sería el "más primitivo" y el segundo el "más desarrollado".

Silvert (1976) señala que el término caudillismo alude generalmente a cualquier régimen personalista y cuasimilitar, cuyos mecanismos partidistas, procedimientos administrativos y funciones legislativas están sometidos al control inmediato y directo de un líder carismático y a su cohorte de funcionarios mediadores. Debe su aparición al colapso de una autoridad central, capaz de permitir a fuerzas ajenas o rebeldes al Estado apoderarse de todo el aparato político.

Por su parte, Wiarda y Kryzanek (1977) proponen nueve elementos para caracterizar el caudillismo. Estos no se comprueban en todos los países progresistas. Los gobernantes de los gobiernos progresistas de origen no son aparentemente caudillos, por provenir de la sociedad civil y de la clase política, y no son militares. Las dos excepciones de origen militar son Chávez y Ortega. Sin embargo, revisando las otras características de Wiarda y Kryzanek (ver tabla 2), se puede descartar el caudillismo de los gobiernos progresistas.

\subsection{La reelección permanente}

Un fenómeno derivado del caudillismo es la búsqueda de reelecciones permanentes, partiendo de la premisa de que no hay sustituto para el presidente/ líder del proceso. Si bien hay dos presidentes que están establemente en el 


\section{Tabla 2}

CARACTERÍSTICAS DEL CAUDILliSMO

Propuestas de Wiarda y Kryzanek

Los caudillos vienen generalmente del cuerpo militar y descansan principalmente en los militares para su apoyo y sostenimiento.

El liderazgo del caudillo se caracteriza por un fuerte estilo personalista y de su manera correspondiente de relacionarse con la ciudadanía. La palabra es el vehículo específico del carisma.

El caudillo gobierna de una manera paternalista y altamente centralizada.

Los caudillos tienden a permanecer en su puesto por un periodo extenso de tiempo (continuismo). La experiencia histórica señala que ningún caudillo permanece poco tiempo en su puesto, y que su salida siempre es forzosa.

Los caudillos generalmente gobiernan de una manera autocrática, que con frecuencia implica la supresión de la oposición, la creación de partidos y movimientos oficiales y la supresión de otros.
Todos tienen un fuerte estilo personalista y utilizan la palabra como el vehículo carismático. Tienen discursos que atrapan al ciudadano en su carisma. El concepto de carisma va definido por la Academia de la Lengua como la capacidad de algunas personas para atraer o fascinar.

Los presidentes electos no gobiernan de manera paternalista. La postura común es que velan por el interés nacional. Gobiernan de manera centralizada. Son regímenes presidencialistas.

Han permanecido en su puesto por un periodo largo porque fueron reelectos y su salida fue democrática. Inclusive en Venezuela el presidente aún no pierde las elecciones (2017) de manera que no está forzando su poder en el sentido clásico. Han respetado los procesos electorales y han dejado el cargo cuando han perdido las elecciones, como Lula da Silva en Brasil, Rafael Correa en Ecuador y Cristina Fernández en Argentina. Otros quieren permanecer eternamente en el cargo como Daniel Ortega, Evo Morales y Nicolás Maduro en Venezuela. Parece haber una tentación a la reelección indefinida, en tres de siete países.

En líneas generales no ha suprimido a la oposición, aunque se hayan y estén enfrentados con ella. Hubo algunos intentos marginales de suprimir voces discordantes, como el cierre de las ONG en Bolivia o el encarcelamiento de líderes de la oposición en Venezuela, pero no son los rasgos que marcan a los gobiernos progresistas, sino son casos extremos y excepcionales.

Gobierno, Ortega y Maduro, este no es el caso de los demás. Evo Morales hizo un referéndum que votó contra su tercera elección y, aunque insistirá, su deseo de correr por tercera vez en el 2019 se verá enfrentado al Poder Judicial. 
Los caudillos han evitado generalmente lo que los estadounidenses llamarían normas democráticas de gobierno; en su lugar, tienden a erigir sistemas estatales orgánicos

Los caudillos generalmente desarrollan políticas públicas designadas para enriquecerse ellos y a su clientela, y a preservar el statu quo que ellos han establecido. El resultado a mediano y largo plazo es la descapitalización del país; e inflación y cuentas difíciles de pagar a los acreedores externos e internos.

Los caudillos tienden a ver poca diferencia entre el dominio público y el privado; ellos operan dentro de una concepción patrimonialista y con frecuencia usan su puesto y el aparato del Gobierno para su ganancia personal.

Aunque los caudillos pueden gobernar de una manera autoritaria, que es con frecuencia un reflejo de las propias normas y expectativas generales de su propia sociedad, ellos pueden ser no completamente totalitarios.
No parecen haber erigido sistemas estatales orgánicos, sino más bien siguen las normas democráticas, excepción hecha por Maduro ("Haremos elecciones con o sin oposición") y Ortega (colocó a su esposa de vicepresidenta; a Laureano Ortega, su hijo, de jefe de ProNicaragua; y a Rafael Ortega, otro hijo suyo, jefe de la Distribuidora Nicaragüense de Petróleos, entre otros familiares en el Estado)."

El manejo de las cuentas fiscales responde en muchos casos a políticas económicas heterodoxas y por tanto no se han ceñido a las metas por inflación. Esto tiene que ver con la saturación con la ortodoxia.

Han sido acusados de corrupción Lula da Silva y Cristina Fernández, pero no así los otros presidentes en los periodos del año 2000 en adelante. No se observa ni inflación extraordinariamente alta ni cuentas por pagar excesivas, salvo en Venezuela. La deuda de Argentina y los fondos buitres es un tema político al margen de esta característica.

Nicaragua sí entra dentro de esta característica.

Es un rasgo común el que sean autoritarios y patrimonialistas. En Nicaragua se observa la confusión de lo público y lo privado, no así en el resto de gobiernos progresistas, aunque hay acusaciones de corrupción contra Lula y Cristina.

Responden a las demandas de liderazgo de la población.

Correa, Ortega y Maduro son más autoritarios que Morales, Lula o Cristina.

Fuente: Elaboración propia.

* El País, 29 de noviembre del 2016. "El círculo familiar del poder en Nicaragua".

Rafael Correa quiso la reelección indefinida, pero tuvo que poner una elección intermedia donde no podía correr para asegurar su legitimidad. El Gobierno llamado "interino" hizo un referéndum que votó contra la reelección indefinida. Cristina Fernández quiso correr por tercera vez y perdió las elecciones contra la oposición de derecha. Tabaré Vásquez fue electo en Uruguay en el 
2005 por el Frente Amplio, cedió el paso a Pepe Mújica del 2010 al 2015 y este le cedió el paso de regreso a Tabaré Vásquez del 2015 al 2020 respetando las formas democráticas. El caso del PT brasileño es de ser electo Lula da Silva en el 2002 y reelecto en el 2006, luego siguió electa Dilma Rouseff en el 2010 y reelecta en el 2014. Le hicieron un golpe de Estado constitucional en el 2016 y gobierna de manera espuria el presidente golpista Temer hasta el 2018, cuando tocan nuevas elecciones.

Nicaragua y Venezuela son casos ajenos a los anteriores. En estos hay reelección indefinida. En Nicaragua con un Ejército pretoriano al servicio del jefe de Estado y con una oposición muy moderada. En Venezuela el Ejército es institucional y la oposición quiere tomar el poder desde que Maduro fue electo en el 2013 tras la muerte de Hugo Chávez. Es un caso típico de alta inflación y descontrol de las finanzas públicas con acusaciones de corrupción circulando, si bien no han sido fundamentadas en el Poder Judicial. En los Panama Papers ${ }^{5}$ aparecen cuentas de venezolanos, donde hay cuentas de funcionarios del Gobierno, así como de líderes de la oposición. No es el caso en los Paradise Papers ni en los Swiss Papers, donde los políticos de oposición sí tienen cuentas, pero no los del Gobierno. Desde la llegada al poder de Nicolás Maduro en el 2013, fue reelecto en el 2017 en una batalla frontal con la oposición dispersa.

Desde este punto de vista, hay una tentación a la reelección indefinida en algunos países, pero también hay una resistencia fuerte a esto. Lo que se demuestra en cambio es que la búsqueda de la reelección indefinida es por no existir líderes alternativos como en Uruguay y Brasil. Es decir, existe reelección indefinida en dos de siete países, no la hay en dos de siete, y se estuvo buscando eso en tres de siete, sin éxito. En todos los casos de búsqueda de reelección indefinida, se trata de problemas de recambio y falta de otros liderazgos.

\subsection{Falta de renovación en la visión social}

Lo que ha ocurrido en los gobiernos progresistas es que se han incorporado sectores de la población a la economía y la política que no lo estaban antes. Desde sectores indígenas y afroamericanos, hay un proceso de incorporación a la vida pública y de restauración de su dignidad que se aprecia notablemente en Venezuela, Bolivia y Brasil. En Ecuador, al revés, el Gobierno

5 "Venezuela and Panama to Launch Joint Panama Papers Investigation". Recuperado de: https://panamapapers.icij.org/20160629-venezuela-panama-inquiry.html. 
de la Revolución Ciudadana, y en palabras de Rafael Correa, fustigó a la CONAIE y marginó a los sectores indígenas del poder político. El Frente Sandinista también tiene una política adversa a la población étnica de los misquitos. Los mapuches argentinos no sintieron una mejora en su situación durante la gestión de los Kirchner. ${ }^{6}$ Esto hace que no se pueda hablar de manera concluyente de la relación de los gobiernos progresistas con todos los sectores marginados. Por lo pronto, desde el punto de vista étnico y racial hay diferencias marcadas.

En cuanto los derechos sexuales y reproductivos, estos incorporaron otros sectores ciudadanos a la política. Los avances fueron dispares: cuatro países pasaron leyes legalizando el aborto y tres no lo hicieron y están abiertamente en contra. El derecho al matrimonio igualitario se aprobó en tres países, está en proceso en otro y está vetado en los otros tres. Es decir, los países progresistas no tienen una agenda de derechos sexuales y reproductivos en común habiendo unos más conservadores que otros en este tema. Esto depende de la influencia de los sectores católicos de extrema derecha, los evangélicos y finalmente el peso del Partido Comunista tradicional. Cuba es el ejemplo de esto último, si bien no lo revisamos en la misma categoría de países progresistas por estar en una categoría aparte.

Los derechos de la juventud para los partidos políticos convencionales se expresan en la fracción juvenil del partido. Sin embargo, sea que no hay partidos políticos grandes o que sean muy cerrados, la necesidad de escuchar las demandas juveniles está presente. Lo que hace la ley de juventudes en general es aclarar los deberes y derechos de los jóvenes y establecer el rango de edad cuando se define como joven a una persona. Va desde los catorce hasta los veintinueve años, pero hay países donde es desde los dieciséis hasta los veintiocho años. La incorporación de la población joven al discurso político de los gobiernos progresistas abre una nueva relación entre el Gobierno y la ciudadanía, y entre el Estado y la juventud en términos de defender derechos, brindar servicios y responder a las demandas.

Cabe notar que los tres países que tienen el nivel de sindicalización más alto de los países progresistas no han creado leyes de juventud y que los que tienen baja sindicalización sí las han creado. Puede tener que ver con el (des) (sub)empleo de los jóvenes en algunos países versus otros donde deben ser protegidos de otra manera. Brasil, Argentina y Uruguay son tres países donde

6 "Argentina: un grito mapuche contra el Gobierno". Recuperado de: https:/www.servindi.org/actuali$\mathrm{dad} / 73078$. 
Tabla 3

LOS DERECHOS SOCIALES EN LOS PAÍSES PROGRESISTAS

\begin{tabular}{|c|c|c|}
\hline País & Periodo de Gobierno & Derechos sociales \\
\hline Argentina & $\begin{array}{l}2003-2007 \\
2007-2011 \\
2011-2015\end{array}$ & $\begin{array}{l}\text { Frente para la Victoria } \\
\text { Ley de Aborto: sí. } \\
\text { Matrimonio igualitario: sí. } \\
\text { No hay ley especial de juventudes. }\end{array}$ \\
\hline Bolivia & $\begin{array}{l}2005-2009 \\
2009-2014 \\
2014-2019\end{array}$ & $\begin{array}{l}\text { MAS } \\
\text { Ley de Aborto: sí. } \\
\text { Matrimonio igualitario: no. } \\
\text { Ley de la Juventud, } 21 \text { de febrero del } 2013 .\end{array}$ \\
\hline Brasil & $\begin{array}{l}2002-2006 \\
2006-2010 \\
2010-2014 \\
2014-2016\end{array}$ & $\begin{array}{l}\text { Partido de los Trabajadores } \\
\text { Ley de aborto: sí. } \\
\text { Matrimonio igualitario: sí. } \\
\text { No hay ley especial de juventudes. }\end{array}$ \\
\hline Ecuador & $\begin{array}{l}2007-2009 \\
2009-2013 \\
2013-2017 \\
2018-2022\end{array}$ & $\begin{array}{l}\text { Revolución Ciudadana } \\
\text { Ley de Aborto: no. } \\
\text { Matrimonio igualitario: no. } \\
\text { Unión civil: sí. } \\
\text { Derechos de los jóvenes: desde el } 2001 .\end{array}$ \\
\hline Nicaragua & $\begin{array}{l}2007-2012 \\
2012-2017 \\
2017-2021\end{array}$ & $\begin{array}{l}\text { Frente Sandinista para la Liberación Nacional } \\
\text { Ley de aborto: no. } \\
\text { Matrimonio igualitario: no. } \\
\text { Unión civil: no. } \\
\text { Derechos de los jóvenes: sí. }\end{array}$ \\
\hline Uruguay & $\begin{array}{l}2005-2010 \\
2010-2015 \\
2015-2020\end{array}$ & $\begin{array}{l}\text { Frente Amplio } \\
\text { Ley de aborto: sí. } \\
\text { Matrimonio igualitario: sí. } \\
\text { No hay ley especial de juventudes. }\end{array}$ \\
\hline Venezuela & $\begin{array}{l}1999-2007 \\
2007-2012 \\
2013-\end{array}$ & $\begin{array}{l}\text { Movimiento Quinta República y PSUV } \\
\text { Ley de aborto: no. } \\
\text { Matrimonio igualitario: en proceso. } \\
\text { Derechos de los jóvenes: sí. }\end{array}$ \\
\hline
\end{tabular}

Fuente: Elaboración propia.

no se ha atacado la sindicalización durante los gobiernos progresistas y donde existe un aparato productivo formal que permanece. Son tres países donde el tema de la juventud se ve como parte del proceso de desarrollo de la fuerza de trabajo a través de la vida sindical, versus países donde esto no es tan evidente 
y donde otros elementos son tomados en cuenta. La ley boliviana, en su artículo 9 (derechos civiles), por ejemplo, refiere:

Las jóvenes y los jóvenes tienen los siguientes derechos civiles:

1. Respeto a su identidad individual o colectiva, cultural, social, política, religiosa y espiritual, a su orientación sexual, como expresión de sus formas de sentir, pensar y actuar en función a su pertenencia.

Esta explicitación subsana para los jóvenes lo que no está en las leyes generales de la nación. Las sociedades más maduras, sindicalizadas, industrializadas y mejor educadas no tienen leyes para la juventud. Son sociedades donde no se ha desmontado el aparato productivo. Esto no quiere decir que no se necesite de tales leyes, porque la problemática juvenil es específica y creciente: problemas de embarazos no deseados, drogas, desempleo juvenil, tecnificación creciente que se exige para entrar al mercado de trabajo, todos estos son aspectos que deben de ser contemplados en los países y para los cuales debe haber políticas públicas específicas.

\subsection{La corrupción}

El fenómeno de la corrupción, combatido por las izquierdas a partir del imaginario de una nueva moral, parece haber impactado también a los gobiernos progresistas. El escándalo Odebrecht puso sobre la mesa un nuevo tipo de corrupción donde los empresarios apuestan por las elecciones de todos los candidatos con diferentes montos, dependiendo de la probabilidad. Cuando gana alguno, entonces está mejor posicionado para hacer negocios con él. Esto se ha visto con las constructoras brasileñas, pero lo hacen otras empresas que contratan con el Estado de otros países y propios también.

Este fenómeno existía desde siempre, pero recién se hizo a la luz cuando el Departamento de Justicia de los Estados Unidos descubrió las transferencias de la empresa Odebrecht a diversos funcionarios de países latinoamericanos. De esta manera, nos abre la interrogante sobre las formas de operar del capital. ¿Todos deben utilizar la corrupción para competir o para estar adelante en la competencia? Lo notable, sin embargo, es que progresistas y no progresistas recibieron pagos de diferentes magnitudes. En algunos casos es criminal, en otros no, pero en todos los casos se plantea un problema ético.

Al otro lado, se encuentra el argumento de Anne Kruger (1974) de que la burocracia se apropia del Estado para sus propios fines y luego cobra rentas 
para su funcionamiento. Para acabar con esto, nos dice, debería de privatizarse el Estado y reducirlo al mínimo. Sin embargo, la consecuencia a la vista es que la corrupción creció en volúmenes sustantivos, en proporción directa con la cantidad de negocios que se llevan a cabo. La forma de hacer negocios está corroída por pagos indebidos, sea con el Estado o dentro del sector privado. En el mercado todo tiene un precio. La dirección de la corrupción no va desde el funcionario hacia el empresario, sino desde el empresario hacia el político, no el funcionario. Esto es cualitativamente distinto y marca unas nuevas formas de corrupción.

La empresa brasileña que ha puesto el tema sobre la mesa también ha enrostrado que apuesta por políticos de izquierda y de derecha, y que les paga a ministros de uno y otro bando esperando no solo los contratos y su respectiva paga, sino ganancias extraordinarias que surgen de adendas de construcción. Odebrecht ha operado así en doce países, que incluye a la mayor parte de países latinoamericanos, menos Cuba, Bolivia, Chile y Centroamérica (salvo Guatemala). De estos, algunos han tomado medidas de investigación a sus políticos y enfocado medidas punitivas. Otros, con poderes judiciales más débiles y con una prensa menos incisiva, no han tomado mucha acción. La reacción frente a la evidencia de la corrupción abre interrogantes sobre los gobiernos progresistas. Ha sido negativo que hayan recibido pagos políticos de distintos niveles. Y es peor que contra eso no hayan hecho nada al respecto.

Han existido exposiciones múltiples en los Panamá Papers y los Paradise Papers sobre políticos y altos funcionarios con cuentas en dichos paraísos fiscales. En algunos casos, esto no ha sido investigado agregándose al crimen de la compra de políticos o funcionarios, el crimen doble de la impunidad.

Si bien solo hay dos jefes de Estado con acusaciones de corrupción y uno al borde de ir a la cárcel, Lula da Silva, existen numerosos ejemplos de corrupción vistos tanto desde parte de funcionarios altos como los propios jefes de Estado no acusados. El caso de la familia Ortega en Nicaragua es uno que carece de acusaciones dentro de ese país, pero que está visto desde afuera como flagrante. Roberto Rivas Reyes, presidente del Consejo Supremo Electoral (CSE), ha sido incluido en una lista de los Estados Unidos como violador de derechos humanos y corrupto. Igualmente el director de Albanisa, empresa que maneja el petróleo de Venezuela en Nicaragua a medias entre PDVSA y Petronica.

Otros casos análogos son los funcionarios del Gobierno de Brasil que cayeron desde el inicio de las investigaciones de corrupción en el 2012. Esto incluye la plana mayor del PT y de los demás partidos políticos, dejando la 
impresión de que en Brasil todo está corrompido. Parece haber una racha que cubre a los países latinoamericanos al margen de que sean o no progresistas. La corrupción no parece discriminar y la habilidad de los funcionarios tampoco.

Lo que existía antes de la "república de los empresarios" era lo que Krueger llamó "sociedades rentistas". La corrupción consistía en que el funcionario público cobraba por darle al cliente algún beneficio público. Después de las privatizaciones y de las reformas económicas de la década de 1990, todo esto se ha trastocado. El Estado se ha vuelto un botín asaltado desde el sector privado. Se han transformado de sociedades rentistas a sociedades de despojo.

Algunos elementos para la caracterización de la corrupción presentados por el caso Odebrecht son la privatización de la corrupción, los mecanismos para corromper, la transnacionalización del fenómeno y el tamaño del botín público saqueado. Analicemos los dos primeros.

En el caso de la privatización de la corrupción, lo que se aprecia ahora es el impulso desde el sector privado por apostar ganadores a cargos públicos desde donde podrían obtener contratos que devendrían no en ganancias legítimas relacionadas al margen de la ganancia de su actividad económica, sino en trozos del erario público convirtiendo al Estado en un botín saqueable. Los agentes privados despojan al Estado a través de un mecanismo de apuestas similar al del mercado de derivados financieros.

La empresa constructora apostó " $n$ " millones de dólares a que un candidato ganaría las elecciones presidenciales peruanas. Por las dudas apostó por todos los candidatos otorgándoles dinero para sus campañas presidenciales. El sentido de la apuesta empero es que una vez haya triunfado, el ganador aprobaría la renovación de adendas a contratos de construcción hechas por el Ministerio de Transportes y Comunicaciones del país. En el caso de México, lo que se observa es una apuesta doble porque, de un lado, hubo dinero para todas las campañas electorales y, de otro, la entrega de una casa en Ciudad de México y un departamento en Miami al candidato ganador. En el caso mexicano, la empresa española OHL le entregó el bien a la cónyuge del presidente electo. Lo que duplica la apuesta es que además se le entregó dinero al presidente de PEMEX para obras que dicha empresa llevaría a cabo a futuro. Como cualquier apuesta, contiene un elemento de riesgo porque, de un lado, puede ser que los contratos de las obras no las ganen genuinamente ellos y, de otro lado, puede ser que las obras no se lleven a cabo. Un ejemplo es la construcción de un ferrocarril rápido de Ciudad de México a Querétaro, cuya licitación fue suspendida cuando fue destapado el escándalo del pago. 
En estos casos, la corrupción comienza fuera del Estado y llega al funcionario público como una propuesta que no puede rechazar. Así cayeron los empresarios en Brasil antes que los políticos de una docena de países (Angola, Argentina, Brasil, Colombia, República Dominicana, Ecuador, Guatemala, México, Mozambique, Panamá, Perú y Venezuela) señalados por el propio Marcelo Odebrecht de haber recibido dinero suyo. Pero solo en Brasil y Ecuador hay encarcelados.

\section{Tabla 4}

RELACIÓN COSTO BENEFICIO DE LA CORRUPCIÓN NUEVA (EN MILLONES DE DÓLARES)

\begin{tabular}{lccccccc}
\hline País/corrupción & Perú & $\begin{array}{c}\text { República } \\
\text { Dominicana }\end{array}$ & Argentina & Colombia & Ecuador & México & Panamá \\
\hline Sobornos & 29 & 92 & 35 & 11 & 35.5 & 10.5 & 59 \\
Beneficios extra & 143 & 163 & 278 & 50 & 116 & 39 & 175 \\
Relación & $493 \%$ & $177 \%$ & $794 \%$ & $455 \%$ & $327 \%$ & $371 \%$ & $297 \%$ \\
\hline
\end{tabular}

Fuente: http://www.capital.com.pe/mundo/odebrecht-que-paises-recibieron-coimas-y...

Y por el caso de los mecanismos para corromper, la corrupción trasnacional tiene como rasgo que los pagos a candidatos a la presidencia, alcaldes o presidentes de empresas públicas se hacen no dentro de los espacios nacionales de sus "clientes" sino en paraísos fiscales mediante cuentas a nombre de terceros. Así, por ejemplo, los pagos a Pedro Pablo Kuczynski cuando era ministro se hicieron a través de su empresa consultora registrada en Miami, en una cuenta de banco en un paraíso fiscal. De la misma manera están los pagos al expresidente Alejandro Toledo a través de una cuenta análoga. Los pagos a través de conyugues son frecuentes igualmente, como en el caso de México, donde la empresa española que construyó el segundo piso del anillo periférico en el tramo que está en el Estado de México, la que ganó la licitación de los peajes, así como la construcción de un tren rápido en dicho Estado, le regaló a la primera dama una casa en Las Lomas y un departamento en Miami.

Para terminar, la lógica de "ponme donde haya y no me des", donde el funcionario echa mano de fondos públicos o cobra por sus servicios, ha sido sustituida por la del caballo por el que apuesta el agente privado. La relación costo beneficio de la apuesta, según Marcelo Odebrecht, es de 416\% promedio (ver tabla 4), lo que es un fuerte incentivo para los apostadores. Lo interesante es que ha intervenido el Departamento de Justicia de los Estados Unidos en el 
caso Odebrecht, dado que los pagos son trasnacionales (utilizan el SWIFT ${ }^{7}$ de los bancos y pasan por los Estados Unidos una fracción de segundo camino a la cuenta de destino) y en dólares. Así les puso la denuncia en primer lugar a los empresarios que hacían los pagos para la empresa brasileña, aunque todavía no ha ocurrido con los empresarios españoles.

La solución a los casos de corrupción de esta naturaleza es que el Poder Judicial de cada país castigue de manera ejemplar a los políticos involucrados. Todo parece indicar, sin embargo, que existen países donde este es muy débil y no aparecen acusaciones fuertes ni campañas de prensa para hacer visible lo que se ha denunciado internacionalmente. La prensa es tan importante como el Poder Judicial en estos casos, porque les permiten a los ciudadanos presionar y exigir justicia. Con todo, se puede observar que la corrupción no es un monopolio de la derecha enfrentada con la nueva moral desde la izquierda, como se pudo pensar tiempo atrás, en la década de 1960, con el caso de Cuba, por ejemplo.

\subsection{Finalmente: el socialismo del siglo XXI}

Fernando Martínez Heredia (2008, p. 32), el intelectual cubano, definió el socialismo de ahora como aquel que busca "conquistar en un país la liberación nacional y social derrocando al poder establecido y creando un nuevo poder, ponerle fin al régimen de explotación capitalista y su sistema de propiedad, eliminar la opresión y abatir la miseria, y efectuar una gran distribución de las riquezas y de la justicia”. Sobre esta lectura de Martínez Heredia, agrega Hamburger Fernández (2014, p. 137):

Este socialismo se propone lograr un auténtico respeto a la integridad y la dignidad humana y garantizar la alimentación, la salud, la educación y el empleo para todos. Busca, además, hacer respetar el derecho de las mayorías y las promesas de igualdad efectiva de las personas más allá de su ubicación social, género, raza y edad. El gran reto de este tipo de socialismo consistiría en eliminar el subdesarrollo, fundar instituciones y cultura democráticas y crear un Estado de derecho en un ambiente de relaciones económicas internacionales más justas. En este socialismo se hace necesario también, como en el primero, crear una nueva cultura, diferente y opuesta a la del capitalismo.

7 SWIFT (Society for Worldwide Interbank Financial Telecommunication) es una organización que tiene a cargo una red internacional de comunicaciones financieras entre bancos y otras entidades similares. 
Claudio Lomnitz (2017) señala que "lo de Venezuela no es, ni ha sido, socialismo; ni del siglo XXI, ni de ningún otro siglo. Caudillismo desbocado del siglo XXI, quizá. Redistribución de la renta petrolera a sectores populares —a veces con recursos bastante creativos y positivos - también. Pero ¿un nuevo socialismo democrático? ¿Un enfoque creativo ante la economía del siglo XXI? No". Con esto se abre la discusión sobre si el tema de la forma de la democracia es a esencia de los gobiernos progresistas o si tiene que ver con el régimen de acumulación.

Planteando que sea el régimen de acumulación, el tipo de propiedad es esencial y eso va con las formas de la democracia. Estos no fueron temas en general discutidos ni planeados en los gobiernos que estaban intentado fortalecer los mercados internos, mejorar la distribución del ingreso y darle más estabilidad a la economía que estaba volátil por el apego primario exportador. Acosta dice que los gobiernos progresistas solo fueron administradores del capitalismo en crisis en estos países. En todo caso, para llegar al cielo se necesita una escalera grande y otra chiquita, y es posible que los gobiernos progresistas hayan usado la escalera chiquita que ha abierto la puerta a pensar de otra manera en los problemas económicos y políticos, cuando se han visto enfrentados a lo que es la lucha de clases con el poder real. Ganar las elecciones no es tomar el poder. Los únicos casos de tomar el poder vistos en el hemisferio americano son Cuba y Nicaragua anteriormente, la que parece haberse convertido en un remedo del Gobierno de Somoza, el cual derrocó. En esos dos casos sí hubo una reconstrucción del poder. El caso nicaragüense es una demostración de que no toda construcción de una nueva democracia acaba en buen puerto y que la corrupción y el caudillismo son rasgos que no son monopolio del capitalismo dependiente. 


\section{Bibliografía}

Castro, P. (2008). El caudillismo en América Latina, ayer y hoy. Los movimientos sociales y el problema del Estado. Política y cultura, 27, pp. 9-29.

Da Silva, L. (2002). Carta ao povo brasileiro [Carta al pueblo brasileño]. Recuperado de: http://www.iisg.nl/collections/carta_ao_povo_brasileiro.pdf.

Harnecker, M. (2011). Democracia y socialismo: el futuro enraizado en el presente. Estudios críticos del desarrollo, 1(1), pp.151-182.

Hamburger, A. (2014). El socialismo del siglo XXI en América Latina: características, desarrollos y desafíos. Revista de Relaciones Internacionales: Estrategia y Seguridad, 9(1), pp. 131-154.

Lomnitz, C. (2017). ¿Socialismo del siglo XXI? Opinión. La Jornada (10 de mayo). México D. F.

Martínez Heredia, F. (2008). Socialismo. Cuadernos de Pensamiento Crítico Ruth, 1, pp.13-39. Panamá: Ruth Casa Editorial.

Silvert, K. H. (1976). Caudillismo. En Enciclopedia Internacional de las Ciencias Sociales, t. 2 (p. 223). Madrid: Aguilar.

Wiarda, H. J. y Kryzanek, M. J. (1977). Dominican dictatorship revisited: the caudillo tradition and the regimes of Trujillo and Balaguer. Review Interamericana, 7, pp. 417-418. 